Mitrovic et al., 2022

Volume 7 Issue 3, pp. 57-68

Received: $16^{\text {th }}$ June 2021

Revised: $2^{\text {nd }}$ November 2021, $10^{\text {th }}$ January 2022, 13 th January 2022

Accepted: 17th January 2022

Date of Publication: 19th January 2022

DOI- https://doi.org/10.20319/mijst.2022.73.5768

This paper can be cited as: Mitrović, I., Grahovac, J., Dodić, J., Grahovac, M., Trivunović, Z. E Dodić, S.

(2022). Production of Agents for Biocontrol of Apple Fusarium Rot by Soilborne Streptomycetes. MATTER: International Journal of Science and Technology, 7 (3), 57-68.

This work is licensed under the Creative Commons Attribution-NonCommercial 4.0 International License. To view a copy of this license, visit http://creativecommons.org/licenses/by-nc/4.0/ or send a letter to Creative Commons, PO Box 1866, Mountain View, CA 94042, USA

\title{
PRODUCTION OF AGENTS FOR BIOCONTROL OF APPLE FUSARIUM ROT BY SOILBORNE STREPTOMYCETES
}

\author{
Ivana Mitrović \\ University of Novi Sad, Faculty of Technology Novi Sad, Bulevar Cara Lazara 1, Novi Sad, \\ Serbia \\ tadi@uns.ac.rs

\section{Jovana Grahovac} \\ University of Novi Sad, Faculty of Technology Novi Sad, Bulevar Cara Lazara 1, Novi Sad, \\ Serbia \\ johana@uns.ac.rs

\section{Jelena Dodić} \\ University of Novi Sad, Faculty of Technology Novi Sad, Bulevar Cara Lazara 1, Novi Sad, \\ Serbia \\ klik@uns.ac.rs

\section{Mila Grahovac} \\ University of Novi Sad, Faculty of Agriculture, Trg Dositeja Obradovića 8, Novi Sad, Serbia \\ milapedja@gmail.com

\section{Zorana Trivunović} \\ University of Novi Sad, Faculty of Technology Novi Sad, Bulevar Cara Lazara 1, Novi Sad, \\ Serbia \\ ron@uns.ac.rs
}




\title{
Siniša Dodić \\ University of Novi Sad, Faculty of Technology Novi Sad, Bulevar Cara Lazara 1, Novi Sad, Serbia \\ dod@uns.ac.rs
}

\begin{abstract}
Within this paper, the potential of Streptomyces hygroscopicus in biocontrol of two isolates of Fusarium avenaceum isolated from apple fruits in the storage was tested. Production of $S$. hygroscopicus biocontrol agent was performed in 3 l stirred tank bioreactor at an aeration rate of $1.5 \mathrm{vvm}$ and mixing speed of $150 \mathrm{rpm}$. Bioprocess was realized at $26 \pm l^{\circ} \mathrm{C}$ for 168 hours. The activity of bioagents production was tested using in vitro diffusion method with wells. Also, residual glycerol, residual nitrogen content, and cell biomass were determined to analyze bioprocess parameters. The results showed that the highest production of bioagents was observed in $96 h$ of cultivation when the largest zone diameters were formed against $F$. avenaceum KA12 and KA13 of $40.67 \pm 1.15$ and $43.33 \pm 0.58 \mathrm{~mm}$, respectively. The activity of the produced bioagents was confirmed in planta research, where the difference between necrosis diameter of treated and control samples were 2.79 (for KA12) and 2.17 (for KA13) times smaller.
\end{abstract}

\section{Keywords}

Biocontrol, Bioprocess, Fusarium Avenaceum, Streptomyces Hygroscopicus.

\section{Introduction}

The emergence of overpopulation and an increasing number of people around the world has led to the intensification of agricultural activities aimed at direct food production (Önder \& Kamil, 2019). The key to a healthy life is reflected in consuming healthy food (Adedokun, Ojewola \& Ahamefule, 2018). Apple fruit is one of the most widely used fruits in the world. Adults, children, and babies as well use this important food not only as fruit but also as processed in the form of compotes, jams, baby food, and more. However, during storage, transport, and marketing, apple fruit can be infected with various phytopathogenic fungi. This is expected given that the apple is full of water and sugar, which is a good medium for microorganisms.

Phytopathogenic fungi from genera Penicillium, Monilinia, Colletotrichum, and Alternaria are considered the most common causes of apple disease in storage. However, in the last few years fungi of the genus Fusarium have been increasingly mentioned as causes of apple diseases in 
storages (Wenneker et al., 2016; Juhnevica-Radenkova, Radenkova \& Seglina, 2016; Sever, Ivić, Kos, \& Miličević, 2012). Certain species of fungi are especially important for humans due to the possibility of producing mycotoxins harmful to human health. The most important fungi, producers of mycotoxins are Alternaria, Fusarium, and Penicillium genera, and their presence on apple fruits must be controlled (Gashgari et al., 2019; Bjelić et al., 2018).

The intensive application of synthetic pesticides in modern agriculture has led to several side effects that are primarily related to environmental pollution. Some of the most significant disadvantages of synthetic fungicides are: contamination of crop products with harmful chemical residues; contamination of soils and groundwater; health risks to those who apply agrichemicals; genetic resistance; most chemical pesticides are nonspecific etc. Because of that, scientists around the world are making efforts to find alternative methods to replace the use of synthetic chemicals, and one alternative way is the use of beneficial microorganisms (Grahovac et al., 2020). Many scientists have confirmed that the genus Streptomyces has great potential in the production of various secondary metabolites many of which can be used against fungal pathogens (Mitrović et al., 2021; Mojićević et al., 2017; Singh \& Rai, 2012; Sadhasivam, Shanmugam \& Yun, 2010). Streptomycetes are generally not considered pathogenic to humans. Many scientists around the world were studying the use of various streptomycetes and their secondary metabolites. In particular, when it comes to their use in biological control, many products such as Mycostop (Streptomyces griseoviridis K61) and Actinovate (Streptomyces lydicus) have been produced and used (Olanrewaju \& Babalola, 2019).

This paper aims to analyze the bioprocess of bioagents production in a laboratory bioreactor using the production microorganism, S. hygroscopicus. This is important to determine at which moment of bioprocess the highest production of an antifungal bioagent effective against two $F$. avenaceum isolate occurs. The efficacy of cultivation medium supernatant will be tested in vitro and in planta every $12 \mathrm{~h}$ of the bioprocess.

\section{Material and Methods}

To fully understand the bioprocess of biocontrol agents production obtained by the cultivation of S. hygroscopicus in a laboratory bioreactor, appropriate methods for sample analysis were selected. Sampling was performed at precisely defined intervals, and the obtained samples were further analyzed. The methods were chosen to give the clearest possible results of this research. 


\subsection{Streptomycetes and Strain Preparation}

Soilborne Streptomyces hygroscopicus was stored in the Faculty of Technology Novi Sad, Serbia in the Microbial Culture Collection (GenBank accession number KT026467).

Medium used for the strain preparation had the following composition: glucose (15 g/l), soybean meal (10 g/l), CaCO3, (3 g/l), NaCl, (3 g/l), MgSO4, (0.5 g/l), (NH4) $)_{2} \mathrm{HPO}_{4},(0.5 \mathrm{~g} / \mathrm{l})$, $\mathrm{K}_{2} \mathrm{HPO}_{4},(1 \mathrm{~g} / \mathrm{l})$. The $\mathrm{pH}$ of the medium was adjusted to $7.2 \pm 0.1$ before autoclaving. The inoculum was prepared on a rotary shaker at $150 \mathrm{rpm}$, for $72 \mathrm{~h}$.

\subsection{Fungal Pathogens}

Fusarium avenaceum isolates labeled as KA12 and KA13 were used in this study as isolates to be tested. The isolates were obtained and identified as described in the paper by Grahovac et al. (2020).

\subsection{Residual Nutrients Determination}

For the determination of nitrogen and glycerol content in the sample, the cultivation liquid sampled every $12 \mathrm{~h}$ of the bioprocess, was centrifuged. To obtain the supernatant required for further analysis, the liquid was centrifuged for 10 minutes at 10,000 rpm.

The Kjeldahl method was used for the determination of nitrogen content (EPA Manual). The content of residual glycerol was determined by UHPLC as described in the paper of Mitrović et al. (2021).

\subsection{Biomass Determination}

The sampled cultivation liquid was centrifuged for 10 minutes at 10,000 rpm and the supernatant was discarded. The cell pellet was re-suspended in distilled water and the centrifugation procedure was repeated. The resulting precipitate was dried at $105^{\circ} \mathrm{C}$ overnight and then measured. The experiment was done in two replicates (Meanwell \& Shama, 2008).

\subsection{Bioreactor Experiment}

Production of agents for biocontrol of two Fusarium avenaceum apple phytopathogens was realized in a bioreactor (BiostatAplus, Sartorius AG, Germany). A used bioreactor is adequate for laboratory experiments with a volume of 31 . During $168 \mathrm{~h}$ of bioprocess aerobic conditions were enabled by the application of a $1.5 \mathrm{vvm}$ aeration rate and $150 \mathrm{rpm}$ mixing speed. Other process parameters were controlled automatically. 
A $10 \%$ of fresh prepared S. hygroscopicus culture was inoculated in the bioreactor, containing following media composition: glycerol $(20 \mathrm{~g} / \mathrm{l}),\left(\mathrm{NH}_{4}\right)_{2} \mathrm{SO}_{4}(0.25 \mathrm{~g} / \mathrm{l}), \mathrm{K}_{2} \mathrm{HPO}_{4}(1.5 \mathrm{~g} / \mathrm{l})$, $\mathrm{CaCO} 3(3 \mathrm{~g} / \mathrm{l}), \mathrm{NaCl}(3 \mathrm{~g} / \mathrm{l})$ and $\mathrm{MgSO}_{4}(0.5 \mathrm{~g} / \mathrm{l})$ at $\mathrm{pH} 7.0 \pm 0.1$.

\subsection{In Vitro and in Planta Testing}

Diffusion method with wells was used to examine the activity of produced $S$. hygroscopicus bioagents against F. avenaceum KA12 and KA13 in vitro (Tadijan, Grahovac, Dodić, Grahovac \& Dodić, 2016).

To confirm the effect of the produced bioagents on the stored apple fruits, in planta testing was performed. Testing was performed on the Golden Delicious apple fruits according to the method described by Mitrović et al., 2021. Each apple fruit was surface sterilized with 70\% ethanol for 2 minutes. After that, the apple fruits were washed with sterile distilled water. In artificially made wounds $(4 \times 3 \mathrm{~mm})$, first was added $10 \mu \mathrm{l}$ of $S$. hygroscopicus supernatant and then mycelial plug ( $3 \mathrm{~mm}$ diameter) of the tested fungal isolate ( $F$. avenaceum KA12 and KA13) into each wound. Sterile water was used as a control treatment. The fruits were incubated in a plastic container at a temperature of $21-23^{\circ} \mathrm{C}, 97 \%$ relative humidity. The diameter of developed necrotic lesions on the inoculated fruits was measured 10 days after inoculation.

\section{Results and Discussions}

The results of this work were obtained by monitoring the bioprocess of biocontrol agent production using the microorganism S. hygroscopicus. Within the results, the course of this bioprocess was examined, by monitoring the change in the consumption of the most important media nutrients and the amount of generated biomass. Also, the results show the effect of produced bioagents using in vitro and in planta tests on two phytopathogens of storage apple fruits, $F$. avenaceum KA12 and KA13.

\subsection{Substrate Consumption and Cell Growth}

Substrate consumption and cell growth were monitored during 168 hours of $S$. hygroscopicus cultivation. This is significant given that the increase in biomass and substrate consumption can indicate at which point the exponential phase ends and the stationary phase of the bioprocess begins. 


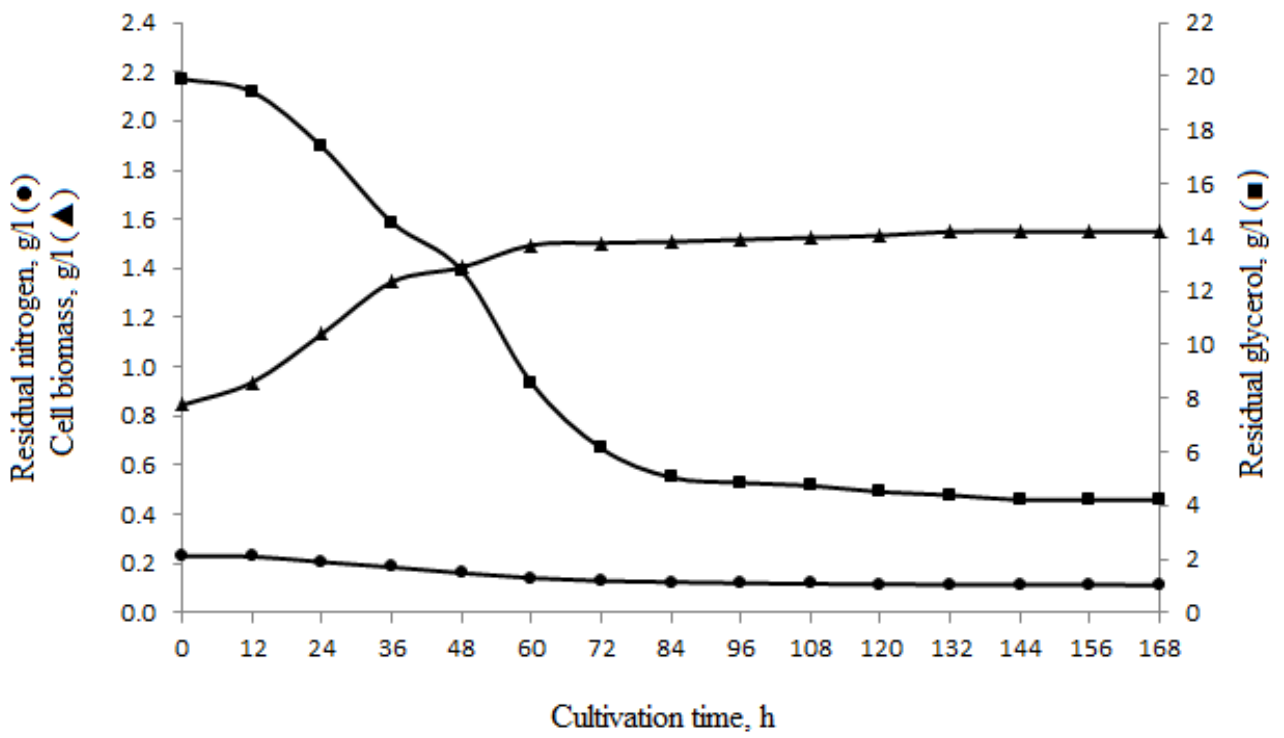

Figure 1: Substrate consumption and cell growth during $168 \mathrm{~h}$ of

Streptomyces hygroscopicus cultivation

(Source: Data obtained in the experiment)

According to the fact that $S$. hygroscopicus produces secondary metabolites during the stationary phase, from Figure 1, it can be concluded that this phase begins after $72 \mathrm{~h}$ of the bioprocess.

Results of glycerol testing during cultivation (Fig. 1) show that the value of this nutrient was significantly consumed by the third day of bioprocess because microbial cells were intensively consumed glycerol for growth and biomass production. A similar flow was shown by the nitrogen utilization curve during the bioprocess (Fig. 1). As with glycerol, consumption of nitrogen decreases significantly until the third day.

Also, in accordance with the consumption of the two most important nutrients, at the same time, there is an increase in the cells biomass of the production microorganism, S. hygroscopicus (Fig. 1). Similar nutrient consumption was observed in the work of Tadijan et al. 2016. However, faster consumption of the carbon source in their work is due to the fact that the most suitable carbon source for streptomycetes is glucose (Kanini, Katsifas, Savvides \& Karagouni, 2013; Singh, Mazumder \& Bora, 2009). Certainly, in addition to glucose, glycerol has been reported by some scientists as the most suitable for the production of antifungal metabolites from the Streptomyces genera (Singh \& Rai, 2012). 
Based on Figure 1 it can be seen that the exponential phase of the bioprocess ends after the third day when the stationary phase, the phase in which S. hygroscopicus produce antifungal metabolites, begins.

\subsection{In Vitro Results}

In vitro method represents the first step in the testing of the efficacy of produced bioagents against phytopathogenic isolates. Based on the obtained inhibition zone diameters it can be concluded at which hour of the bioprocess the largest production of bioagents occurs.

Following Figure 1, Figure 2 shows that no antifungal bioagents were produced until the third day of cultivation. After the third day, there was a gradual increase in the zone diameter of the $F$. avenaceum KA12 and KA13 mycelial growth. The largest diameter of inhibition zone formed on isolates $F$. avenaceum KA12 and KA13 was observed on the fourth day of (96 h of cultivation).

By analyzing Figure 2 it can be concluded that the $F$. avenaceum KA12 isolate was more resistant to the produced antifungal bioagents, forming a maximum mean value of mycelial growth inhibition zone diameter of $40.67 \mathrm{~mm}$. At the same time, the maximum mean value of the mycelial growth diameter of the inhibition zone for $F$. avenaceum KA13 isolate at 96 hours of cultivation was $43.33 \mathrm{~mm}$. After $96 \mathrm{~h}$ of cultivation, there was a gradual decrease in the efficiency of antifungal bioagents produced by $S$. hygroscopicus. Since these are isolates of the same species, similar results obtained in the experiment were expected. These results are related to the results obtained in the work of Grahovac et al., 2020, which was done on a similar medium composition but using different conditions of mixing and aeration of the cultivation liquid. 


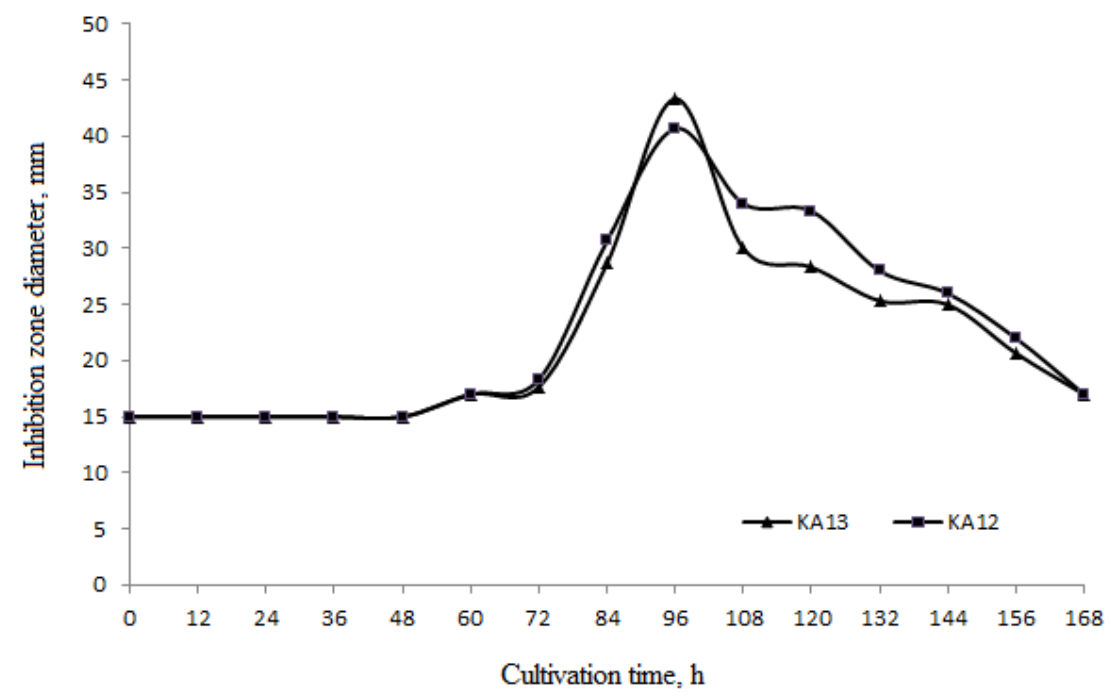

Figure 2: Mean values of mycelial growth inhibition diameter $(\mathrm{mm})$ for $F$. avenaceum KA12 and KA13 isolates caused by S. hygroscopicus supernatant

(Source: Data obtained in the experiment)

It is assumed that the favorable conditions in the bioreactor are the result of large inhibition zone diameters formed on isolates $F$. avenaceum KA12 and KA13. This is expected since Yen and $\mathrm{Li}$ (2014) proved that an aeration rate of $1.5 \mathrm{vvm}$ was best for rapamycin production by using $S$. hygroscopicus. Similar results were obtained by Sousa, Lopes \& Pereira (2002) by examining $S$. parvulus and actinomycin $\mathrm{D}$ production.

\subsection{In Planta Results}

To confirm the obtained in vitro results, the next step is an in planta experiment. Table 1 shows the results of necrosis obtained after 10 days of incubation of apple fruits treated with supernatant S. hygroscopicus (obtained in $96 \mathrm{~h}$ of cultivation) and necrosis results of control samples.

The results show that there was a statistically very significant difference between the treated samples and the control $(\mathrm{p}<0,01)$.

Table 1. Mean values of necrosis diameter on treated and control apple fruits

after incubation of 10 days

\begin{tabular}{|l|c|c|}
\hline \multirow{2}{*}{ Pathogen } & \multicolumn{2}{|c|}{ Necrosis diameter $\pm \mathrm{Sd}(\mathrm{mm})$} \\
\cline { 2 - 3 } & Artificially inoculated apple fruits & Control samples \\
\cline { 2 - 3 } & Bioprocess 3 1 & \\
\hline F. avenaceum KA12 & $6.68 \pm 0.58$ & $18.68 \pm 0.58$ \\
\hline F. avenaceum KA13 & $7.68 \pm 1.15$ & $16.68 \pm 1.15$ \\
\hline
\end{tabular}


(Source: Data obtained in the experiment)

Results in Table 1 show that the difference between necrosis diameter of treated and control samples were 2.79 (for KA12) and 2.17 (for KA13) times smaller.

\section{Conclusion}

The results obtained in this paper show the good potential of S. hygroscopicus in biocontrol of stored apples from fungal disease caused by $F$. avenaceum isolates. The biocontrol agents produced by $S$. hygroscopicus in the laboratory bioreactor with a mixing speed of $150 \mathrm{rpm}$ and aeration rate of $1.5 \mathrm{vvm}$ show a significant effect against phytopathogenic isolates $F$. avenaceum KA12 and KA13. In vitro experiments and in planta experiments realized in this study show the high efficiency of produced bioagents. Based on the obtained results, it can be concluded that in $96 \mathrm{~h}$ of cultivation the highest efficiency of S. hygroscopicus supernatant on phytopathogenic isolates of $F$. avenaceum KA12 and KA13 was achieved. In practical terms, this means that the bioprocess can be shortened from 7 days to 4 days, making this bioprocess more economical. This research represents the first step towards increasing the volume of this production process. Therefore, as a continuation of the research, a scale-up should be done. This implies the further examination of $S$. hygroscopicus biocontrol agent production on a larger scale under the conditions obtained in this paper. Also, given that the cost of bioagents production is quite high, ways to reduce production costs should be considered. One of the possibilities is certainly the use of adequate waste effluents instead of synthetic substrates, which would significantly affect the cost of production.

\section{Acknowledgments}

This work was supported by the Ministry of Education, Science and Technological Development of the Republic of Serbia under the Program for financing scientific research work, No. 451-03-9/2021-14/200134.

\section{REFERENCES}

Adedokun, O.O., Ojewola, G.S. \& Ahamefule, F.O. (2018). Preliminary investigation of the nutritive potential of umucass 36 cassava root meal as substitute for maize in broiler 
diets. International Journal of Science and Technology, 4(3), 79-86. https://doi.org/10.20319/mijst.2018.43.7986

Bjelić, D., Ignjatov, M., Marinković, J., Milošević, D., Nikolić, Z., Gvozdanović-Varga, J. \& Karaman, M. (2018). Bacillus isolates as potential biocontrol agents of Fusarium clove rot of garlic. Zemdirbyste-Agriculture, 105 (4), 369-376. https://doi.org/10.13080/z-a.2018.105.047

EPA (1979): EPA Manual 351.2. Determination of total Kjeldahl nitrogen by semi-automated colorimetry. 1979. Report No. EPA 60014-79-020

Gashgari, R., Ameen, F., Al-Homaidi, E., Gherbawy, Y., Al Nadhari, S. \& Vijayan, V. (2019). Mycotoxigenic fungi contaminating wheat; toxicity of different Alternaria compacta strains. Saudi Journal of Biological Science, 26, 210-215. https://doi.org/10.1016/j.sjbs.2018.10.007

Grahovac, J., Mitrović, I., Dodić, J., Grahovac, M., Rončević, Z., Dodić, S. \& Jokić, A. (2020). Biocontrol agent for apple Fusarium rot: optimization of production by Streptomyces hygroscopicus. Zemdirbyste-Agriculture, 107 (3), 263-270. https://doi.org/10.13080/za.2020.107.034

Juhnevica-Radenkova, K., Radenkova, V. \& Seglina, D. (2016). Influence of 1-MCP treatment and storage conditions on the development of microorganisms on the surface of apples grown in Latvia. Zemdirbyste-Agriculture, 103 (2), 215-220. https://doi.org/10.13080/za.2016.103.028

Kanini, G., Katsifas, E., Savvides, A. \& Karagouni, A. (2013). Streptomyces rochei ACTA1551, an indigenous Greek isolate studied as a potential biocontrol agent against Fusarium oxysporum .sp. lycopersici. BioMed Research International, 1-10. https://doi.org/10.1155/2013/387230

Meanwell, R.J.L. \& Shama, G. (2008). Production of streptomycin from chitin using Streptomyces griseus in bioreactors of different configurations. Bioresours Technology, 99, 5634-5639. https://doi.org/10.1016/j.biortech.2007.10.036

Mitrović, I., Grahovac, J., Hrustić, J., Jokić, A., Dodić, J., Mihajlović, M. \& Grahovac, M. (2021). Utilization of waste glycerol for the production of biocontrol agents nigericin and niphimycin by Streptomyces hygroscopicus: bioprocess development. Environmental Technology, https://doi.org/10.1080/09593330.2021.1913241 
Mojićević, M, Grahovac, J, Petković, M, Vučković, I., Dodić, J., Dodić, S. \& Vojnović, S. (2017). Production of nigericin and niphimycin by soil isolate Streptomyces sp. MS1: anti-candida bioassay guided response surface methodology for the optimized culture medium. Facta Universitatis, Series Physics, Chemistry and Technology, 15 (1), 1-16. https://doi.org/10.2298/FUPCT1701001M

Olanrewaju, O.S. \& Babalola, O.O. (2019). Streptomyces: implications and interactions in plant growth promotion. Applied Microbiology and Biotechnology, 103(3): 1179-1188. https://doi.org/10.1007/s00253-018-09577-y

Önder, U. \& Kamil, E. (2019). Design of mobile and functional photobioreactor. International Journal of Science and Technology, 4(3), 150-156. https://doi.org/10.20319/mijst.2019.43.150156

Sadhasivam, S., Shanmugam, P. \& Yun, K. (2010). Biosynthesis of silver nanoparticles by Streptomyces hygroscopicus and antimicrobial activity against medically important pathogenic microorganisms. Colloids and Surfaces B: Biointerfaces, 81, 358-362. https://doi.org/10.1016/j.colsurfb.2010.07.036

Sever, Z., Ivić, D., Kos, T. \& Miličević, T. (2012). Identification of Fusarium species isolated from stored apple fruit in Croatia. Archives of Industrial Hygiene and Toxicology, 63 (4), 463-470. https://doi.org/10.2478/10004-1254-63-2012-2227

Singh, L.S., Mazumder, S. \& Bora, T.C. (2009). Optimisation of process parameters for growth and bioactive metabolite produced by a salt-tolerant and alkaliphilic actinomycete, Streptomyces tanashiensis strain A2D. Journal of Medical Mycology, 19, 225-233. https://doi.org/10.1016/j.mycmed.2009.07.006

Singh, N. \& Rai, V. (2012). Optimization of cultural parameters for antifungal and antibacterial metabolite from microbial isolate; Streptomyces rimosus MTCC 10792 from soil of Chhattisgarh. International Journal of Pharmacy and Pharmaceutical Sciences, 4, 94-101.

Sousa, M.F.V.Q., Lopes, C.E. \& Pereir N. (2002). Development of a bioprocess for the production of actinomycin-D. Brazilian Journal of Chemical Engineering, 19(3), 277285. https://doi.org/10.1590/S0104-66322002000300002

Tadijan, I., Grahovac, J., Dodić, J., Grahovac, M. \& Dodić, S. (2016). Effect of cultivation time on production of antifungal metabolite(s) by Streptomyces hygroscopicus in laboratoryscale bioreactor. Journal of Phytopathology, 164, 310-317. https://doi.org/10.1111/jph.12458 
Wenneker, M., Pham, K. T. K., Lemmers, M. E. C., de Boer, F. A., van der Lans, A. M., van Leeuwen, P. J., Hollinger, T. C. \& Thomma, B. P. H. J. (2016). First report of Fusarium avenaceum causing wet core rot of 'Elstar' apples in the Netherlands. Plant Disease, 100 (7), 1501. https://doi.org/10.1094/PDIS-01-16-0034-PDN

Yen, H.W. \& Li, Y.L. (2014). The effects of viscosity and aeration rate on rapamycin production in an airlift bioreactor by using Streptomyces hygroscopicus. Journal of the Taiwan Institute of Chemical Engineers, 45, 1149-1153. https://doi.org/10.1016/j.jtice.2014.01.014 